\title{
Effect of chemically reduced graphene oxide on epoxy nanocomposites for flexural behaviors
}

\author{
Seul-Yi Lee', Mi-Hwa Chong ${ }^{1}$, Mira Park ${ }^{2}$, Hak-Yong Kim ${ }^{2, *}$ and Soo-Jin Park ${ }^{1, *}$ \\ ${ }^{1}$ Department of Chemistry, Inha University, Incheon 402-751, Korea \\ ${ }^{2}$ Department of OrganicMaterials and Fiber Engineering, Chonbuk National University, Jeonju 561-756, Korea
}

\section{Article Info}

Received 25 October 2013

Accepted 26 December 2013

\section{*Corresponding Author \\ E-mail: sjpark@inha.ac.kr khy@chonbuk.ac.kr \\ Tel: $+82-32-8767234$ \\ $+82-63-2702351$ \\ Open Access \\ DOI: http://dx.doi.org/ \\ 10.5714/CL.2014.15.1.067}

This is an Open Access article distributed under the terms of the Creative Commons Attribution Non-Commercial License (http://creativecommons.org/licenses/ by-nc/3.0/) which permits unrestricted non-commercial use, distribution, and reproduction in any medium, provided the original work is properly cited.

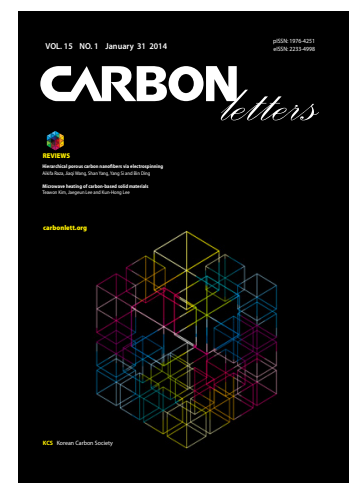

http://carbonlett.org

pISSN: 1976-4251

elSSN: 2233-4998

Copyright $\odot$ Korean Carbon Society

\begin{abstract}
In this work, nanocomposites of epoxy resin and chemically reduced graphene oxide (RGO) were prepared by thermal curing process. X-ray diffractions confirmed the microstructural properties of RGO. Differential scanning calorimetry was used to evaluate the curing behaviors of RGO/epoxy nanocomposites with different RGO loading amounts. We investigated the effect of RGO loading amounts on the mechanical properties of the epoxy nanocomposites. It was found that the presence of RGO improved both flexural strength and modulus of the epoxy nanocomposites till the RGO loading reached $0.4 \mathrm{wt} \%$, and then decreased. The optimum loading achieved about 24.5 and $25.7 \%$ improvements, respectively, compared to the neat-epoxy composites. The observed mechanical reinforcement might be an enhancement of mechanical interlocking between the epoxy matrix and RGO due to the unique planar structures.
\end{abstract}

Key words: chemically reduced graphene oxide, epoxy, nanocomposites, mechanical properties

\section{Introduction}

Graphene, the thinnest known material in the cosmos, exhibits many outstanding properties, like extremely high strength $(\sim 130 \mathrm{GPa})$ and modulus ( 1000 GPa) [1], high thermal conductivity $\left(\sim 5000 \mathrm{~W} /\left(\mathrm{m}^{3} \cdot \mathrm{K}\right)\right)$ [2], and very high electrical conductivity $(\sim 6000 \mathrm{~S} / \mathrm{cm})[3]$, all due to its $\mathrm{sp}^{2}$-hybridized carbon atoms.

There have been many studies on graphene synthesis methods; the most common synthesis method is a top-down processing of graphite to graphene oxide (GO) by strong oxidation and mechanical exfoliation [4]. GO is an insulator by nature due to an abundance of oxygen-functional groups, but it can be reduced chemically or thermally to form electrically conductive graphene materials.

Graphene has been used as a nanofiller in a wide range of polymer matrices including polystyrene [5], polyurethane [6], polypropylene [7], polycarbonate [8], poly(vinyl alcohol) [9], and so on. Graphene based nanocomposites have been investigated for their superior electrical, thermal, and mechanical properties [10-12]. The incorporation of various nano-sized reinforcements into an epoxy matrix can maximize the advantages of structural composites [13-15]. Remarkable improvements in physical and mechanical properties of polymer composites have been reported upon the addition of a small amount of graphene [16-18].

In order to enhance the properties of graphene based nanocomposites, improving the dispersion of the graphene in polymer has remained the most important issue to be resolved. It is well known that graphene will normally become entangled due to intermolecular van der Waals forces and will aggregate in the polymer matrix. The resulting poor dispersion of graphene significantly lowers its efficiency as a reinforcement, and in particular, can lead to a different impact on the mechanical properties of polymer composites. A variety of processing methods, including in situ polymerization, melt mixing, and solution blending, have been proposed to disperse graphene in polymer matrix $[19,20]$. 


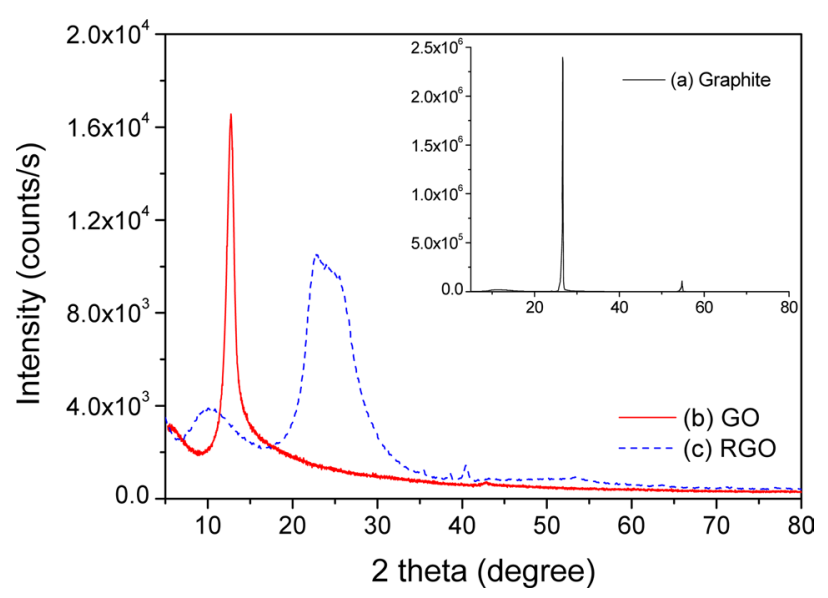

Fig. 1. Wide X-ray diffraction patterns of graphite (a), graphene oxide (GO) (b), and reduced GO (RGO) synthesized in this study (c).

In this work, we prepared chemically reduced GO (RGO) for use as a mechanically enhancing filler in an epoxy matrix. The nanocomposites of epoxy resin with RGO were prepared by thermal curing process. The flexural properties of the RGO/ epoxy nanocomposites were investigated as a function of RGO loading amount.

\section{Experimental}

\subsection{Materials and sample preparation}

GO was produced using the Hummers' method as a starting material for graphene [21]. The chemically reduced GO was prepared as follows: 1) $1 \mathrm{~g}$ of GO was dispersed into distilled water using ultra-sonication; 2) $1 \mathrm{~g}$ of hydroquinone was added to the GO solution, and the mixture was heated to $150^{\circ} \mathrm{C}$ for $24 \mathrm{~h}$; 3 ) the GO solution was thoroughly dried at $80^{\circ} \mathrm{C}$ in a vacuum oven after washing with distilled water and ethanol at a ratio of 1:1.

The epoxy polymer used in this study was diglycidyl ether of bisphenol A, supplied by Kukdo Chem. of Korea (YD-128, an epoxide equivalent weight of 185-190 g/eq, a density of approximately $1.16 \mathrm{~g} / \mathrm{cm}^{3}$ at $25^{\circ} \mathrm{C}$ ). 4,4>-Diaminodiphenyl methane was used as a curing agent for the epoxy polymer. The epoxy polymer and RGO powder were fed into a beaker, with ultra-sonication at $80^{\circ} \mathrm{C}$ for $12 \mathrm{~h}$ to enhance the dispersion state of the RGO in the epoxy matrix. The composites were mixed with RGO at the weight percent loading range of $0-0.5 \mathrm{wt} \%$. The stoichiometric amount of curing agent was added to the RGO/ epoxy mixtures. The mixtures were poured into a designed mold and degassed at $120^{\circ} \mathrm{C}$ for $20 \mathrm{~min}$ in a vacuum oven. Then, the curing processes were performed, at $120^{\circ} \mathrm{C}$ for $1 \mathrm{~h}$ and $150^{\circ} \mathrm{C}$ for $2 \mathrm{~h}$. Finally, samples were post-cured at $180^{\circ} \mathrm{C}$ for $1 \mathrm{~h}$ in a convection oven.

\subsection{Characterization}

The micro-structural characteristics of the GO and RGO were investigated using X-ray diffraction (XRD, Model D2 Phaser, BRUKER Co.). The curing behaviors were monitored by differ-

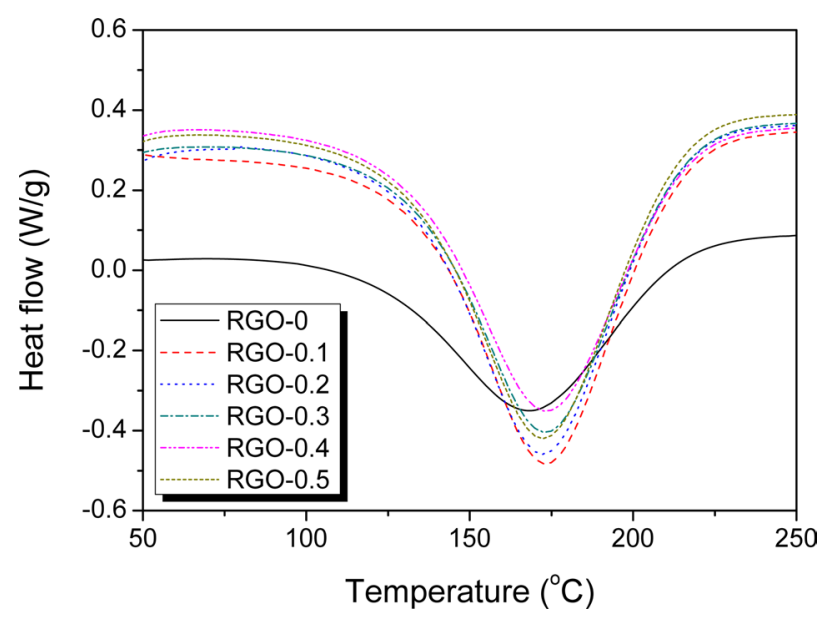

Fig. 2. Differential scanning calorimetry curves of reduced graphene oxide (RGO)/epoxy nanocomposites with different RGO loading amounts.

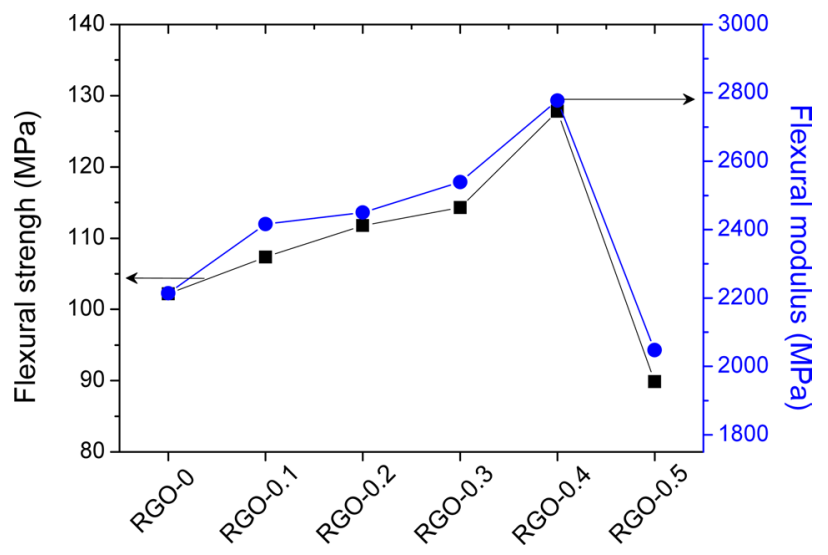

Fig. 3. Flexural strength and modulus of graphene oxide (RGO)/epoxy composites with different RGO loading amounts.

ential scanning calorimetry (DSC, Model DSC 200, NETZSCH Co.) from 50 to $250^{\circ} \mathrm{C}$ at a heating rate of $10^{\circ} \mathrm{C} / \mathrm{min}$ under an $\mathrm{N}_{2}$ flow. The flexural properties were measured by an Instron universal testing machine (UTM, Model LR5K, LLOYD Co.) according to ASTM D-790. The average values were obtained from the results of five tests. The fracture surfaces of RGO/epoxy composites after the flexural stress test were observed by scanning electron microscopy (SEM, Model S-4200, Hitachi Co.).

\section{Results and Discussion}

XRD patterns of graphite showed an intensive diffraction (002) peak at 2 theta $=26.6^{\circ}$, reflecting a $d$-spacing of $3.35 \AA$ between the graphitic interlayers. It was found that a well-defined diffraction peak of GO was observed at 2 theta $=12.8^{\circ}$, indicating that the interlayer spacing or gap increased to $6.91 \AA$. After the chemical reduction, the asymmetric diffraction peak of RGO was revealed at around 2 theta $=11^{\circ}$ and $24^{\circ}$. This result confirmed that the RGO were exfoliated into stacking layered sheets.

DSC curves of the RGO/epoxy mixtures are shown in Fig. 2, 


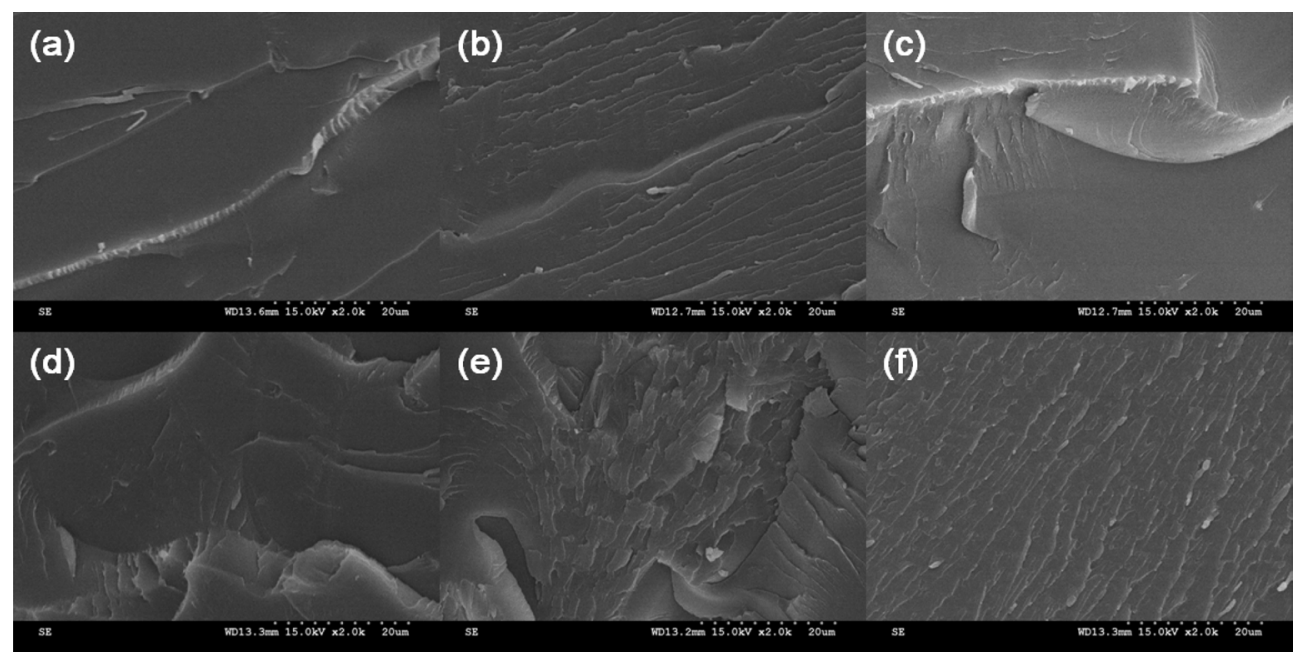

Fig. 4. Scanning electron microscope images of graphene oxide (RGO)/epoxy nanocomposites; (a) RGO-0, (b) RGO-0.1, (c) RGO-0.2, (d) RGO-0.3, (e) RGO0.4 , and (f) RGO-0.5.

investigating the curing behaviors of the RGO/epoxy nanocomposites. All samples showed a single exothermic peak at a high temperature, more than $150^{\circ} \mathrm{C}$, originating from the decomposition of functional groups in the epoxy-based composites [18]. The main exothermic peaks of RGO/epoxy nanocomposites were observed to be at a higher temperature than those for neat-epoxy composites. It was confirmed that this was due to the steric hindrance effect on the curing process with the addition of RGO particles. The higher volume fraction of RGO increased the surface area in contact with the epoxy matrix, which could anchor the chain mobility $[22,23]$.

The effect of the RGO loading amounts on the mechanical properties of RGO/epoxy nanocomposites was investigated with flexural measurements. As shown in Fig. 3, the enhancement effect produced by the presence of RGO can be clearly distinguished. The flexural properties increased with increasing RGO loading amounts up to $0.4 \mathrm{wt} \%$, and then decreased. The flexural strength and modulus of RGO-0.4 was determined to be 102 and $2210 \mathrm{MPa}$, respectively. It was found that the enhancement of flexural properties was strongly related to the interfacial adhesion between the RGO and epoxy matrix. The overloading of RGO (RGO-0.5) produced poor flexural properties, resulting from the aggregation of RGO in the epoxy matrix. Excessive interfacial contacts, between both the RGO/RGO and RGO/matrix, weaken the flexural properties of RGO/epoxy nanocomposites [24]. From the results, we found that the appropriate amount of RGO led to a superior reinforcement effect in the matrix.

To understand the influence of added RGO on the mechanical properties of the epoxy nanocomposites, the fracture surfaces of the samples after impact tests were characterized with SEM, as shown in Fig. 4. A smooth surface (Fig. 4) was observed in the RGO-0 sample. The fracture surfaces of the RGO/epoxy nanocomposites appeared rougher and more varied in comparison with RGO-0, indicating that higher fracture energy was required $[25,26]$. However, the sample with excessive RGO loading, RGO-0.5, exhibited an agglomeration of RGO and some defects in the matrix. It was found that in this case the RGO had acted as stress concentrators and reduced the strengthening effects of RGO in the matrix [26].

\section{Conclusions}

In this work, we prepared chemically RGO for use as a mechanically enhancing filler in an epoxy matrix. The mechanical properties of the RGO/epoxy nanocomposites were investigated as a function of RGO loading amount. From the results, it was found that the flexural strength and modulus of RGO/epoxy nanocomposites were $\sim 24.5 \%$ and $\sim 25.7 \%$ greater, respectively, than those of the neat epoxy composites, when the added RGO amount was $0.4 \mathrm{wt} \%$.

\section{Acknowledgements}

This research was financially supported by the Ministry of Education, Science Technology (MEST) and National Research Foundation of Korea (NRF) through the Human Resource Training Project for Regional Innovation (No. 2012-10-A-04-046-13010100).

\section{References}

[1] Lee C, Wei X, Kysar JW, Hone J. Measurement of the elastic properties and intrinsic strength of monolayer graphene. Science, 321, 385 (2008). http://dx.doi.org/10.1126/science.1157996.

[2] Balandin AA, Ghosh S, Bao W, Calizo I, Teweldebrhan D, Miao F, Lau CN. Superior thermal conductivity of single-layer graphene. Nano Lett, 8, 902 (2008). http://dx.doi.org/10.1021/n10731872.

[3] Du X, Skachko I, Barker A, Andrei EY. Approaching ballistic transport in suspended graphene. Nat Nanotechnol, 3, 491 (2008). http://dx.doi.org/10.1038/nnano.2008.199.

[4] Lee SY, Park SJ. Comprehensive review on synthesis and adsorption behaviors of graphene-based materials. Carbon Lett, 13, 73 (2012). http://dx.doi.org/10.5714/CL.2012.13.2.073.

[5] Stankovich S, Dikin DA, Dommett GHB, Kohlhaas KM, Zimney EJ, Stach EA, Piner RD, Nguyen ST, Ruoff RS. Graphene- 
based composite materials. Nature, 442, 282 (2006). http://dx.doi. org/10.1038/nature04969.

[6] Jung YC, Kim JH, Hayashi T, Kim YA, Endo M, Terrones M, Dresselhaus MS. Fabrication of transparent, tough, and conductive shape-memory polyurethane films by incorporating a small amount of high-quality graphene. Macromol Rapid Commun, 33, 628 (2012). http://dx.doi.org/10.1002/marc.201100674.

[7] Song P, Cao Z, Cai Y, Zhao L, Fang Z, Fu S. Fabrication of exfoliated graphene-based polypropylene nanocomposites with enhanced mechanical and thermal properties. Polymer, 52, 4001 (2011). http://dx.doi.org/10.1016/j.polymer.2011.06.045.

[8] Potts JR, Murali S, Zhu Y, Zhao X, Ruoff RS. Microwave-exfoliated graphite oxide/polycarbonate composites. macromolecules, 44 , 6488 (2011). http://dx.doi.org/10.1021/ma2007317.

[9] Salavagione HJ, Martínez G, Gómez MA. Synthesis of poly(vinyl alcohol)/reduced graphite oxide nanocomposites with improved thermal and electrical properties. J Mater Chem, 19, 5027 (2009). http://dx.doi.org/10.1039/B904232F.

[10] Shiu SC, Tsai JL. Characterizing thermal and mechanical properties of graphene/epoxy nanocomposites. Composites B, 56, 691 (2014). http://dx.doi.org/10.1016/j.compositesb.2013.09.007.

[11] Wang X, Jin J, Song M. An investigation of the mechanism of graphene toughening epoxy. Carbon, 65, 324 (2013). http://dx.doi. org/10.1016/j.carbon.2013.08.032.

[12] Castelain M, Martínez G, Ellis G, Salavagione HJ. A versatile chemical tool for the preparation of conductive graphene-based polymer nanocomposites. Chem Commun, 49, 8967 (2013). http:// dx.doi.org/10.1039/C3CC43729A.

[13] Liang J, Huang Y, Zhang L, Wang Y, Ma Y, Guo T, Chen Y. Molecular-level dispersion of graphene into poly(vinyl alcohol) and effective reinforcement of their nanocomposites. Adv Funct Mater, 19, 2297 (2009). http://dx.doi.org/10.1002/adfm.200801776

[14] Sánchez M, Campo M, Jiménez-Suárez A, Ureña A. Effect of the carbon nanotube functionalization on flexural properties of multiscale carbon fiber/epoxy composites manufactured by VARIM. Composites B, 45, 1613 (2013). http://dx.doi.org/10.1016/j.compositesb.2012.09.063.

[15] Lv S, Ma Y, Qiu C, Sun T, Liu J, Zhou Q. Effect of graphene oxide nanosheets of microstructure and mechanical properties of cement composites. Constr Build Mater, 49, 121 (2013). http://dx.doi. org/10.1016/j.conbuildmat.2013.08.022.

[16] Feng H, Wang X, Wu D. Fabrication of spirocyclic phosphazene epoxy-based nanocomposites with graphene via exfoliation of graphite platelets and thermal curing for enhancement of mechanical and conductive properties. Ind Eng Chem Res, 52, 10160 (2013). http://dx.doi.org/10.1021/ie400483x.

[17] Wan YJ, Tang LC, Yan D, Zhao L, Li YB, Wu LB, Jiang JX, Lai GQ. Improved dispersion and interface in the graphene/epoxy composites via a facile surfactant-assisted process. Composites Sci Technol, 82, 60 (2013). http://dx.doi.org/10.1016/j.compscitech.2013.04.009.

[18] Li Z, Wang R, Young RJ, Deng L, Yang F, Hao L, Jiao W, Liu W. Control of the functionality of graphene oxide for its application in epoxy nanocomposites. Polymer, 54, 6437 (2013). http://dx.doi. org/10.1016/j.polymer.2013.09.054.

[19] Kuilla T, Bhadra S, Yao D, Kim NH, Bose S, Lee JH. Recent advances in graphene based polymer composites. Prog Polym Sci, 35 , 1350 (2010). http://dx.doi.org/10.1016/j.progpolymsci.2010.07.005.

[20] Tang LC, Wan YJ, Yan D, Pei YB, Zhao L, Li YB, Wu LB, Jiang JX, Lai GQ. The effect of graphene dispersion on the mechanical properties of graphene/epoxy composites. Carbon, 60, 16 (2013). http://dx.doi.org/10.1016/j.carbon.2013.03.050.

[21] Hummers WS, Jr., Offeman RE. Preparation of graphitic oxide. J Am Chem Soc, 80, 1339 (1958). http://dx.doi.org/10.1021/ ja01539a017.

[22] Jiang T, Kuila T, Kim NH, Ku BC, Lee JH. Enhanced mechanical properties of silanized silica nanoparticle attached graphene oxide/ epoxy composites. Composites Sci Technol, 79, 115 (2013). http:// dx.doi.org/10.1016/j.compscitech.2013.02.018.

[23] Fang M, Zhang Z, Li J, Zhang H, Lu H, Yang Y. Constructing hierarchically structured interphases for strong and tough epoxy nanocomposites by amine-rich graphene surfaces. J Mater Chem, 20 9635 (2010). http://dx.doi.org/10.1039/C0JM01620A.

[24] Li Z, Young RJ, Wang R, Yang F, Hao L, Jiao W, Liu W. The role of functional groups on graphene oxide in epoxy nanocomposites. Polymer, 54, 5821 (2013). http://dx.doi.org/10.1016/j.polymer.2013.08.026.

[25] Lim SR, Chow WS. Fracture toughness enhancement of epoxy by organo-montmorillonite. Polym Plast Technol Eng, 50, 182 (2011) http://dx.doi.org/10.1080/03602559.2010.531427.

[26] Shen J, Huang W, Wu L, Hu Y, Ye M. The reinforcement role of different amino-functionalized multi-walled carbon nanotubes in epoxy nanocomposites. Composites Sci Technol, 67, 3041 (2007). http://dx.doi.org/10.1016/j.compscitech.2007.04.025. 